\title{
Statistical Analysis of the Average Wind Speeds and Maximum Wind Speed (Gust Winds) at a Location in Abuja, Nigeria
}

\author{
Enoch O. Elemo', Efua A. Ogobor'1, George A. Alagbe'2, Benjamin G. Ayantunji1, \\ Otonye E. Mangete ${ }^{1}$, Oladunjoye S. Tomori ${ }^{1}$, Kemi B. Doherty ${ }^{1}$, Blessing O. Onuh ${ }^{1}$ \\ ${ }^{1}$ Physical and Life Sciences Department, National Space Research and Development Agency, Abuja, Nigeria \\ ${ }^{2}$ Department of Pure and Applied Physics, Ladoke Akintola University of Technonogy, Ogbomoso, Nigeria \\ Email: enochelemo@yahoo.com
}

How to cite this paper: Elemo, E.O., Ogobor, E.A., Alagbe, G.A., Ayantunji, B.G., Mangete, O.E., Tomori, O.S., Doherty, K.B. and Onuh, B.O. (2021) Statistical Analysis of the Average Wind Speeds and Maximum Wind Speed (Gust Winds) at a Location in Abuja, Nigeria. Open Access Library Journal, 8: e7935.

https://doi.org/10.4236/oalib.1107935

Received: September 7, 2021

Accepted: December 3, 2021

Published: December 6, 2021

Copyright $\odot 2021$ by author(s) and Open Access Library Inc.

This work is licensed under the Creative Commons Attribution International License (CC BY 4.0).

http://creativecommons.org/licenses/by/4.0/

\begin{abstract}
Wind speed is widely accepted as the principal driver of the Harmattan season in the West African sub region. It does this by bringing in very huge amount of dust through the Northeast part of Nigeria to the whole country as a whole. The presence of dust in the atmosphere plays a prominent role in the rate of absorptions and scatterings of the solar radiation. However, very little or no attention has been given to the study of Gust winds (short duration (in seconds) wind speed maxima) in Nigeria. Wind gusts represent hazards to property, people, energy sector and transport when severe. The relationships between the average wind speeds and maximum wind speed (gust winds) were studied diurnally for each month over a year period (2020). The study showed some particularly unique results which also might be as a result of the location of the station. The seasonal correlations between the wind speeds and gust winds were very obvious: Both parameters had more stronger values during the dry season than during the season, with both also showing a unique trend in January and February with another different trend from March to December. The degrees of gustiness of the location were studied with the introduction of both Gust factor and Peak factor. Peak factor was however found to be by far the better measure of gustiness than the gust wind factor for the location.
\end{abstract}

\section{Subject Areas}

Atmospheric Sciences

\section{Keywords}

Wind Speed, Gust Wind, Principal Driver, Harmattan, Gustiness, Gust Factor and Peak Factor 


\section{Introduction}

The lack of explanation of the dust mobilization by the large-scale meteorological conditions in the summer gives rise to the emphasis on the local to regional wind systems being linked to the northernmost position of the Jnter-Tropical Convergence Zone (ITCZ) [1]. The climate of the West African region (where Nigeria is) is noted to be dominated by the presence of subtropical pressure belt system that exists over the North Africa near latitude $30^{\circ}$ north and it is what is responsible for the movement of the North East trade wind. The Northeast direction of this trade wind occurs as a result of deflecting force of the earth's rotation (Coriolis force). The trade wind that is known to originates from the subtropical high-pressure belt in the northern hemisphere plays a vital role in influencing the climate of West Africa [2].

Extensive studies done over the region revealed that "shift" in the location of the Inter-Tropical convergence zone (ITCZ) as a result of climatic changes could have immersed consequences on the intensity of the rainfall and the overall state of the region [3] [4]. [5] in its work showed that the position of the ITCZ is noted to experience low pressure and heavy rainfall that are formed by the condensation from moist air that rises as a result of the strong solar heating along the equator, before its divergent poleward near the tropopause. The sensitivity of the ITCZ to solar heating allows it to track the Sun's north-south movement, thereby leading to seasonal distribution experience in the rainfall and the span of the season in the tropics. [3] shows that the ITCZ is actually the interface between the cool, moisture-bearing south-westerlies wind from the Atlantic Ocean, and the dry, hot north-easterlies Continental air mass (CAM) from the Sahara Desert. [6] shows the ITCZ as the bands of clouds are accompanied by occasional thunderstorms. [3] [7] [8] went further to reveal that the ITCZ normally stays in the southernmost position in Nigeria during January and February at a time in the dry season where the North-east winds are prevalent. On the other hand, the raining season is noted to begin in March, and the ITCZ experiences its northernmost position (southern peak) in the month of July as seen in Figure 1. The dry season is between November-February (October-April) in the South (North) and the rest of the months of the year are wet season. [9] described the two types of winds that influence the time and season in Nigeria. The westerly winds (occurs between March and October) are noted to be fairly strong around mid-year and accompany by rain sometimes. The wind is also referred to as Southwest trade wind. The wind comes from the Atlantic oceans. This wind usually is dust-free. On the other hand, the Northeasterly wind occurs from November till February or sometimes March. The wind is noted to be fairly strong and dry most especially in December with a lot of dust (Harmattan). Generally speaking, wind can be said wind occurs to as the flow of different gases within a large area. Wind can be said to be as a result of differential heating of the earth surface by the sun, which leads to difference in Atmospheric pressure. Another reason is the constant rotation of the Earth as its orbit around the Sun. The 


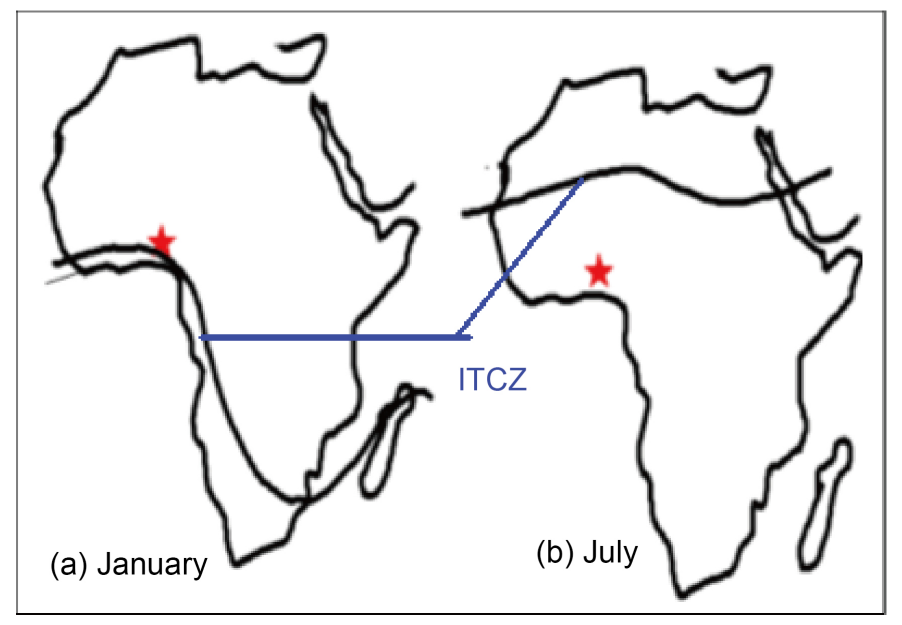

Figure 1. The maps of Africa showing the locations of the ITCZ in (a) January and (b) July. The approximate location of Nigeria is marked with red star after [4].

characteristics of the terrain (buildings mountains, extremely tall trees, or manmade infrastructures so on) definitely also influence the strength of the wind. Wind flow patterns aloft is known to follow isobars or contours where friction has very little effect. However, the presence of friction near the surface cannot be neglected. Friction between the wind and the surface of the terrain slows the wind. This implies that the rougher the terrain, the greater is the frictional effect. Also, the stronger the wind speed, the greater is the friction. As frictional force slows the windspeed, Coriolis force decreases. However, friction does not affect pressure gradient force [10].

On the other hand, a Gust is a sudden and brief increase in the speed of the wind that does not last more than 20 seconds. All gusts are a type of wind. Gust is noted to be of a more transient phenomenon than a squall, which lasts minutes, and this is followed by a lull or weakening in the wind speed [11]. Generally speaking, winds are least gusty over large water surfaces and are mostly gusty over rough land and near sky buildings.

In this paper, we will study the Gust factor and Peak factor between the measured wind speeds and the gust wind, any seasonal relationship in the two based on the location of the station and any other unique characteristics that might result from the fact that the station is a low attitude station.

It is a known fact that, differences in temperature create differences in pressure. These resulting pressure differences create and drive a unique complex system of winds that involves in a never-ending attempt to get to equilibrium [12]. It is also worth noting that wind also transports water vapor and spreads fog, clouds, and precipitation.

[13] revealed, that, the wind speeds in Nigeria range from 2 to $9.5 \mathrm{~m} / \mathrm{s}$, with the trend showing according to the data that the wind speeds are seen to be low in the south and gradually increases to higher wind speeds in the north as seen in Figure 2. 


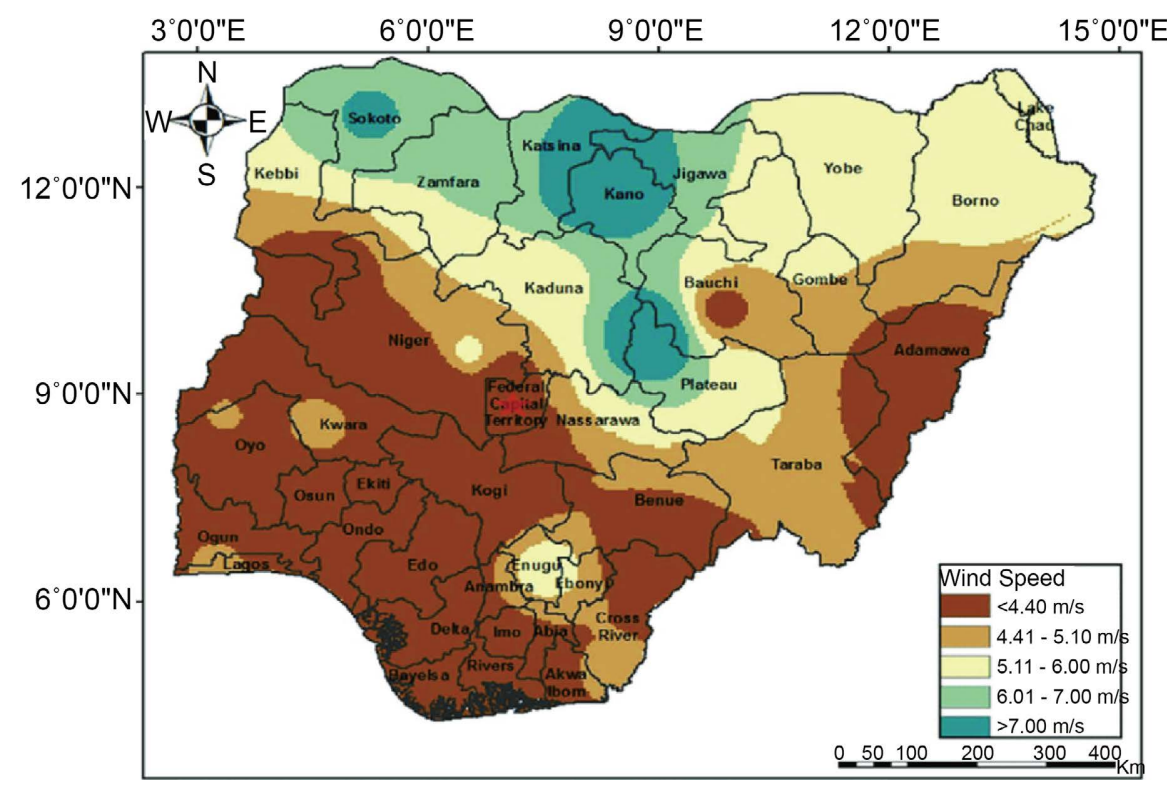

Figure 2. Wind Speed map for Nigeria After [13].

[14] emphasized wind speed as the primary driver of the dry season in the West Africa Sub region. The Northeast trade wind, which is responsible for the convey of a huge amount of dust across the region seasonally, leads to the harmattan season, that is, experience most noticeably between November/December of a particular year, and January till March of the following year. [15] together with [16] raised the importance of the distribution of the variations in wind speed with respect to the impacts of climate variability and change. Wind being one of the elements of climate is known to move from the region of high potential to that of low potential system. "[17] shows that the movement of the wind during the dry season" is determined first by the pressure gradient that is experience in the Sahara Desert, during the low sun period (winter period of the Northern hemisphere). The conclusion from this, is that: how fast the wind moves, depend on how great the pressure of the air is. This led to a conclusive statement that, the wind determines the amount of dust that is brought to the region either seasonally or annually.

[18] shows that the characteristics of the surface roughness near the observation sites significantly affect the characteristics of the wind speed and direction. [18] further characterized surface roughness by many factors that includes: the building coverage ratio, the building volume, ratio of high buildings, average area of buildings and the average height of the building. In his study, [15] classified a "high building" as a building with more than four stories. The values of these other factors were evaluated using a building information database. The atmospheric wind is turbulent over a large range of scales. Wind gusts are noted to be short duration (seconds) wind speed maxima. Therefore, [11] showed that information on wind gusts is strongly needed for thorough assessment of windinduced damage and risks to safety of lives and properties. [19] stated that Long- 
term, continuous and what is called representative wind gust observations should form the basis for risk assessments and wind gust forecasting. The ability to successfully forecast wind gust on a time scales of one day to several weeks ahead are useful according [11] in necessary preparations and actions in various fields of operation. These includes: Shipping [20], aviation [21] [22], energy sector [23] [24] and transport on land [25].

On the other hand, [26] shows that the gust factor depends on wind speed, heights, turbulence intensity and atmospheric stability. The greater the Gust factor, the less the wind speed and vice versa. [26] also indicated that gust factor follows the same asymptotic shape as the turbulence intensity. It however concluded that the Peak factor mainly depends on turbulence intensity and averaging time for gust and mean wind speeds.

\section{Methodology}

The geographical atmospheric parameters in Abuja such as the UV index, temperature, dew point, humidity, wind speed, precipitation rate etc. were measured with the help of meteorological weather station called Davis Vantage Pro 2 Wireless Weather Station. The Davis Vantage Pro 2 records atmospheric parameters in one package called the integrated senor suit (ISS), it was installed at Abuja Wuse $2\left(9.08^{\circ} \mathrm{N}, 7.48^{\circ} \mathrm{E}\right)$, in Nigeria, on the top of a pole at an elevation of approximately $493 \mathrm{~m}$ above the sea level. The data is saved on the data logger affixed to the Davis vantage Pro2 console; the data logger also provides an interface for direct access to the weather station recorded data. The 6510 data logger USB variant was used alongside with the WeatherLink software to store the data on a local computer and also to upload the data to WeatherLink cloud. The sampling was done at $5 \mathrm{mins}$ and it was averaged to one hour for the sake of this paper. For analysis of the measured wind speed and Gust, we used the "Area graph" of the origin software. This allows for a better understanding of the trend both parameters exhibited diurnally, seasonally and any other characteristic due to the location of the station. Using this software: when one Y column of values (or a range from one column) is selected, the "area" between the data plot and the "From" Y axis value is filled by default. That means, when more than one $\mathrm{Y}$ column of values (or a range from more than one column) is selected, each successive column of values displays as an Area graph that is stacked on the previous Area graph. Thus, the upper bound of the previous Area graph becomes the baseline of the next Area graph. [26] described the gust factor as a crude representation of the dynamic properties of the wind, which has been widely accepted as the only measure of turbulence in meteorological measurements. Gust factor can be said to be the ratio between maximum and average wind speed.

$$
G_{T r}=\frac{U \max , r}{U r}
$$

where $U$ max, $r$ is the maximum $\mathrm{T}$-second moving average wind speed during a $r$-second averaging period and $U r$ is the T-second average wind speed accord- 
ing to World Meteorological Organization? Common values for $r$ are mainly 10 minutes or 1 hour. Thus, $G_{T r}$ is proportional to the inverse of the mean wind speed. In practice, the measured $G_{T r}$ values show a large variability at low mean wind speeds, but at strong wind speeds (neutral conditions), G typically reaches a constant value characteristic of the measurement site. The mean $G_{T r}$ depends on various environmental factors, such as the measurement height, surface roughness, atmospheric static stability [11].

A normalized gust factor is defined clearly as the ratio of the maximum wind speed fluctuation and the standard deviation of the longitudinal wind component $(\bar{o})$.

$$
K_{P T r}=\frac{U \max , r-U r}{\overline{0}}
$$

$K_{P T \text { D }}$ which the gustiness parameter is also referred to as "peak factor" where $U r$ and $U \max , r$ are the same as Equation (1).

\section{Results and Discussions}

The rainfall pattern for each month of the year 2020 can be seen in Figure 3. It is distinctively clear that the rainfall started in the month of March (which happens to be the smallest in terms of volume) and ends in October (with 12 days). The month of September had the highest number of days of rainfall and invariably in terms of volume of rainfall too. This is in agreement with [4], which stated that precipitations increase (rainfall peak) during which the ITCZ is in the northern-most position. On the other hand, $99 \%$ of the measured wind speeds at the station, fell within range ( 0 to $4.40 \mathrm{~m} / \mathrm{s}$ ) given by [13] in Figure 3 . The location of the station is represented by "Red star" in the Map. Figure 4 shows the diurnal variations in both the wind speeds and gust wind speeds in everyday of each month of the year 2020. The gust winds values are higher than the measured wind as expected. The diurnal trend can be divided into early morning (00:00 till 06:00 hrs), Daytime (6:00 till 18:00 hrs) and Nighttime (18:00 hrs till 23:00 hrs). The peak of the wind speeds in January occurred at 01:00 hrs while that of the Gust wind speeds for the same month occurred at 03:00 hrs. The strong depression noticed in the graph in the wind speeds during the daytime of the month occurred at 08:00 hrs. While that of the gust wind during the same period occurred at 10:00 hrs. The peak of the wind speeds during the daytime occurred at 11:00 hrs, but that of gust wind was at 13:00 hrs. The strong depression at the later daytime/beginning of nighttime occurred at 18:00 hrs for the wind, but that of gust wind occurred roughly at 19:00 hrs. On the other hand, the peak of the wind speeds in the month of February 2020, occurred at 03:00 hrs and that of gust wind occurred at 05:00 hrs. The "small" depression in the early morning in the wind speeds and gust winds both occurred at 03:00 hrs (same time). A "bigger" depression was more pronounced in the gust winds in the early morning at 06:00 hrs. As the day go by, the values of both wind speed and gust wind decrease. Moreover, both the wind speeds and the gust winds had their lowest 
points in this month at the same time (19:00 hrs). Even though, March had only 15 days data. It still revealed some very important information. Both wind speeds and gusty winds showed almost exactly the same trend in both parameters (same Peak time, lowest point time etc.). However, the time of the lowest point of the both parameters moved from the nighttime period in the earlier two months to the early morning period (07:00 hrs). Another vital point to be noted, is the fact that the exact time of the lowest point of February (19:00 hrs) was the same time as the peak of March. What was distinctively clear from March to December is that, both the Wind speeds and "Gust winds" exhibited very similar trends across the three classifications. The only difference was whether early morning values were greater or less than the night-time values. March, April, May, June, August, October, November and December had their early morning values stronger the nightime values. Whereas, July and September had stronger night time values than morning values.
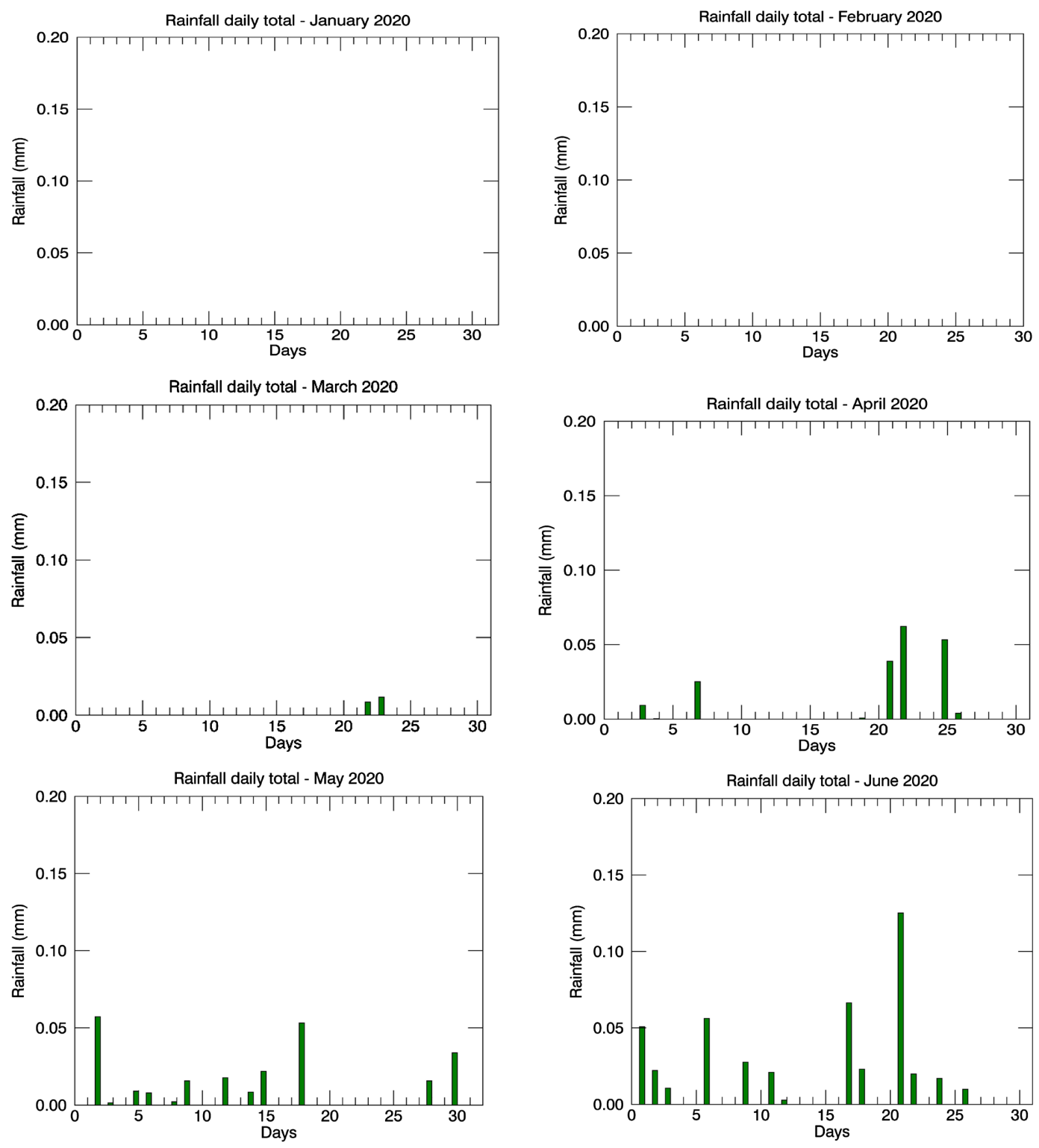


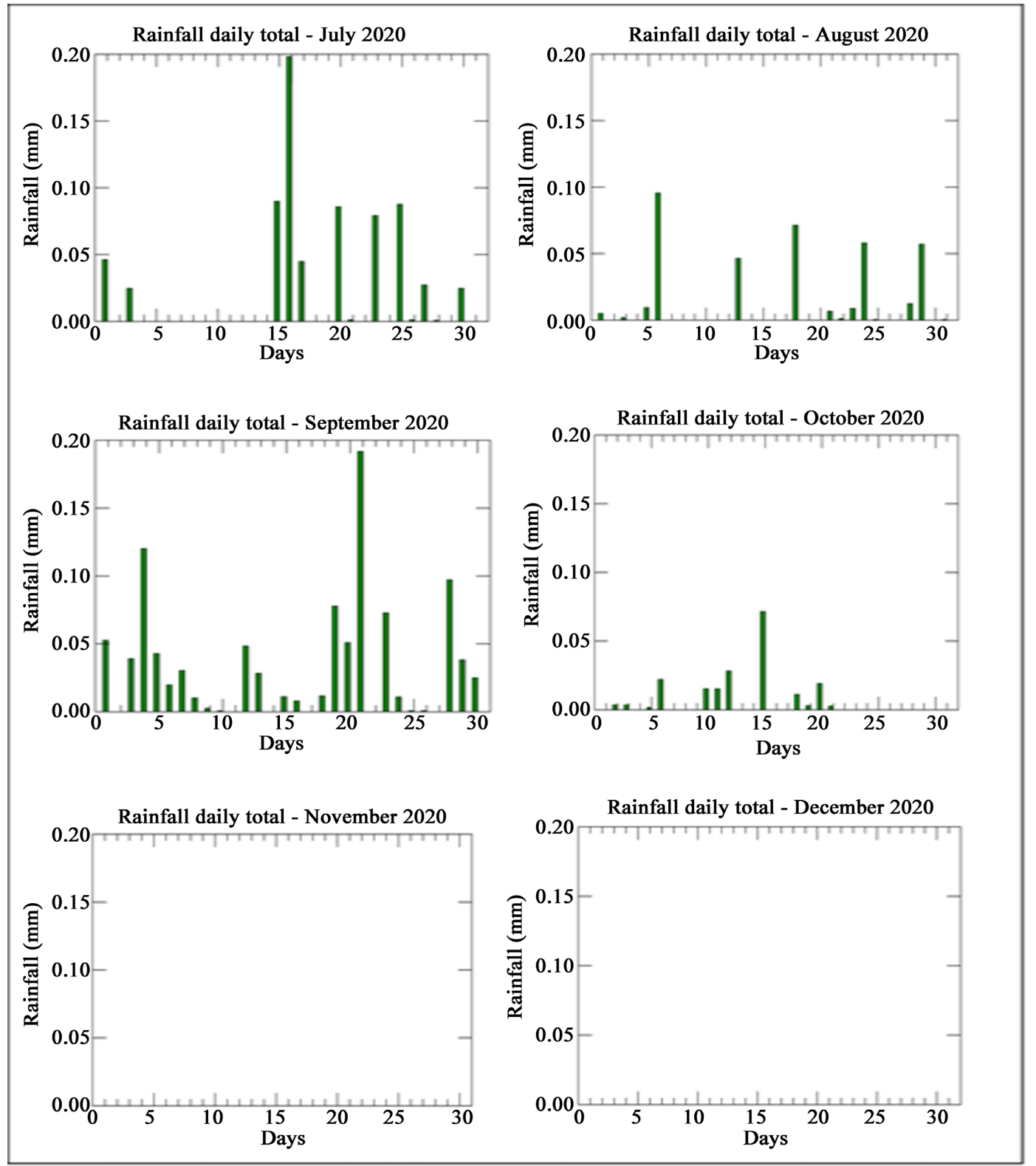

Figure 3. The rainfall pattern for each month of the year 2020.

It is distinctly clear that the trend in the wind speeds and gust wind speeds in January exhibited 2 hours variations (whatever happened to the wind speeds comes two hours before that of the gust wind occurred during the early morning and daytime) and 1 hour variation at their lowest point. The situation in February also showed sometimes 2 hours or same time scenario. This "phenomenon" only happened in January and February alone throughout the whole year. This might be related to the position of the ITCZ at this time of the year.

[4] revealed that a climate-induced little shift in the location of the InterTropical Convergence Zone (ITCZ) "was" noted to have considerable effects on the intensity of rainfall and the overall activities of the region. The ITCZ is in the southernmost position in Nigeria around January-February (A time in which 

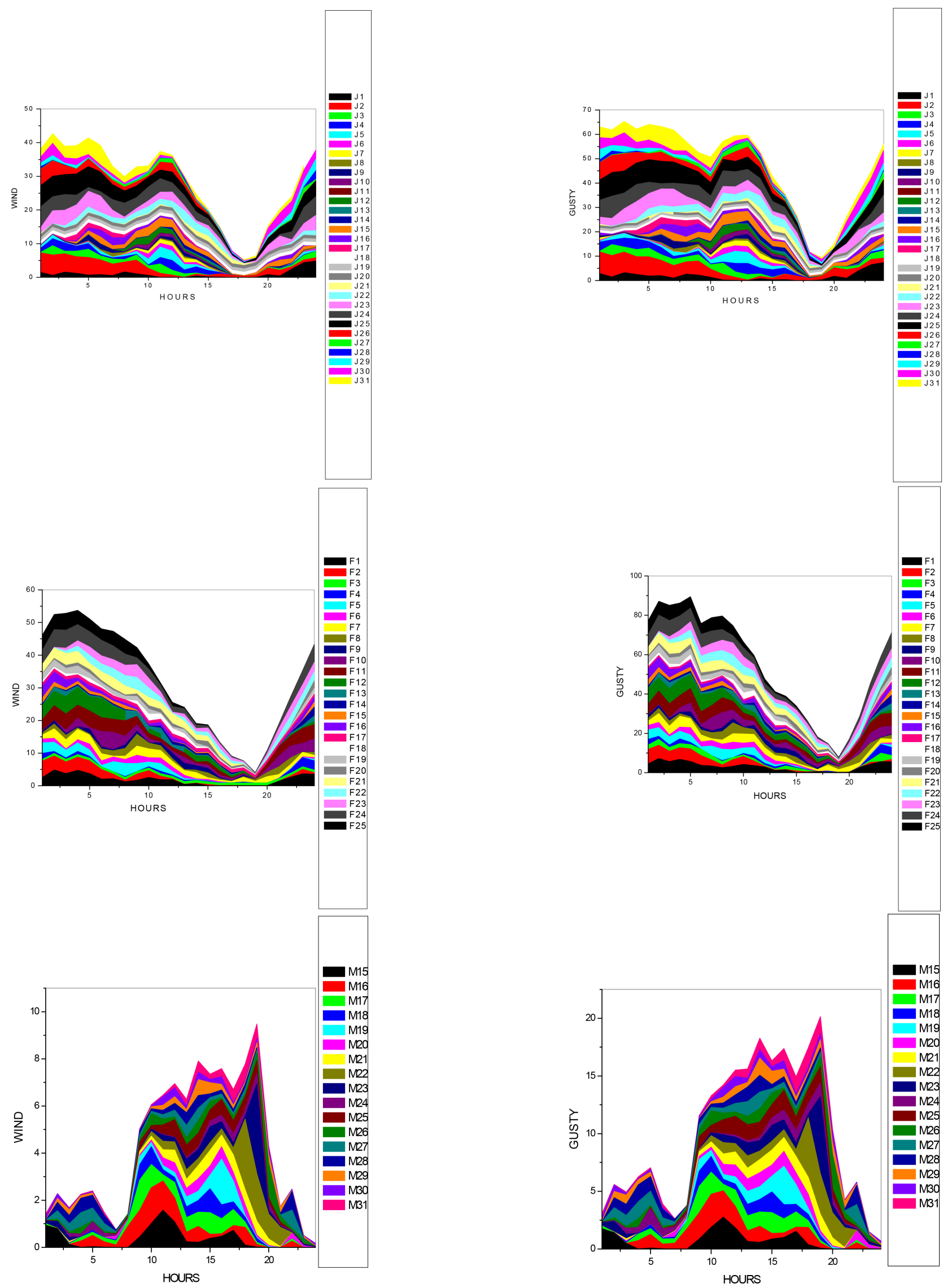

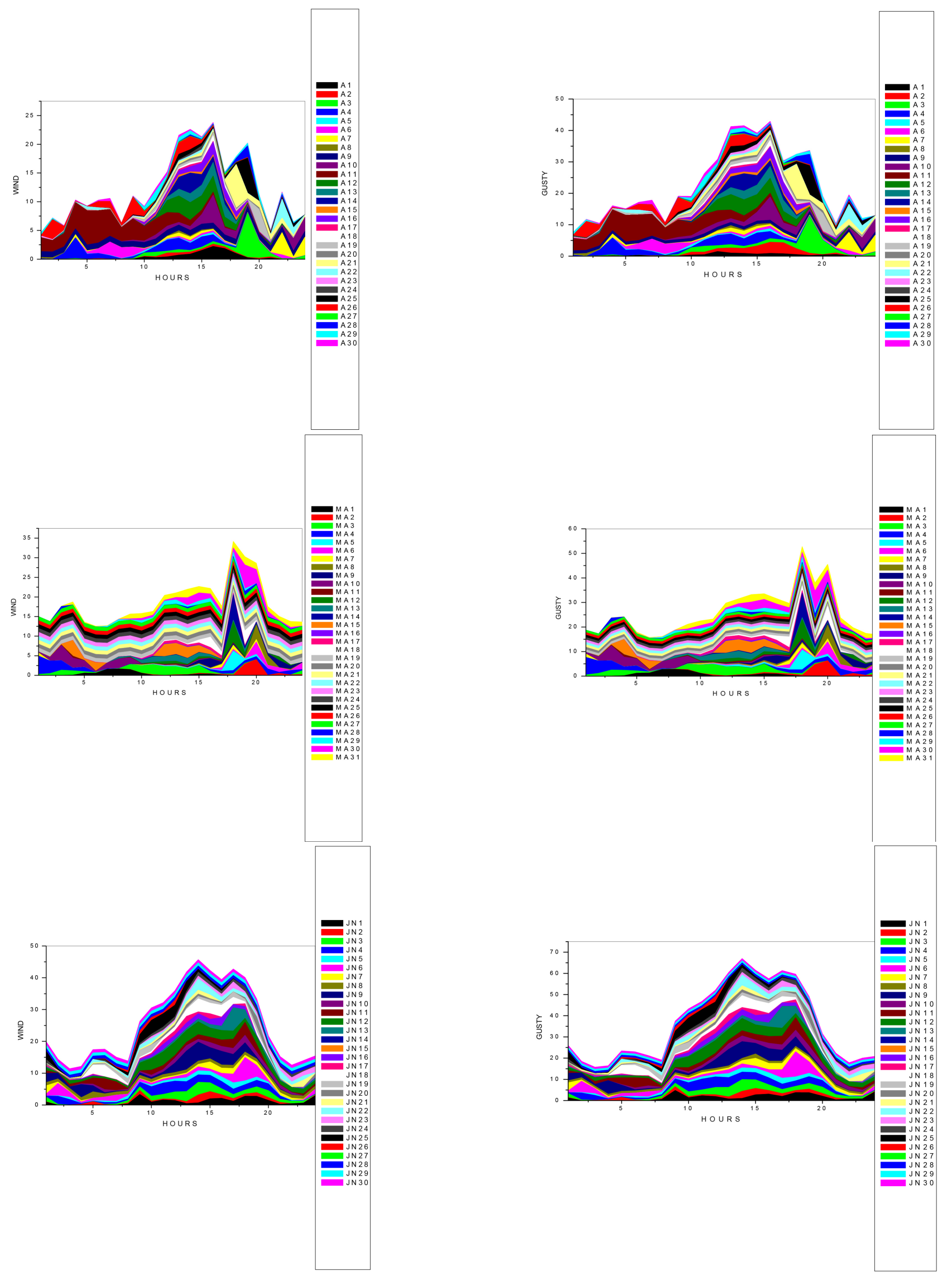

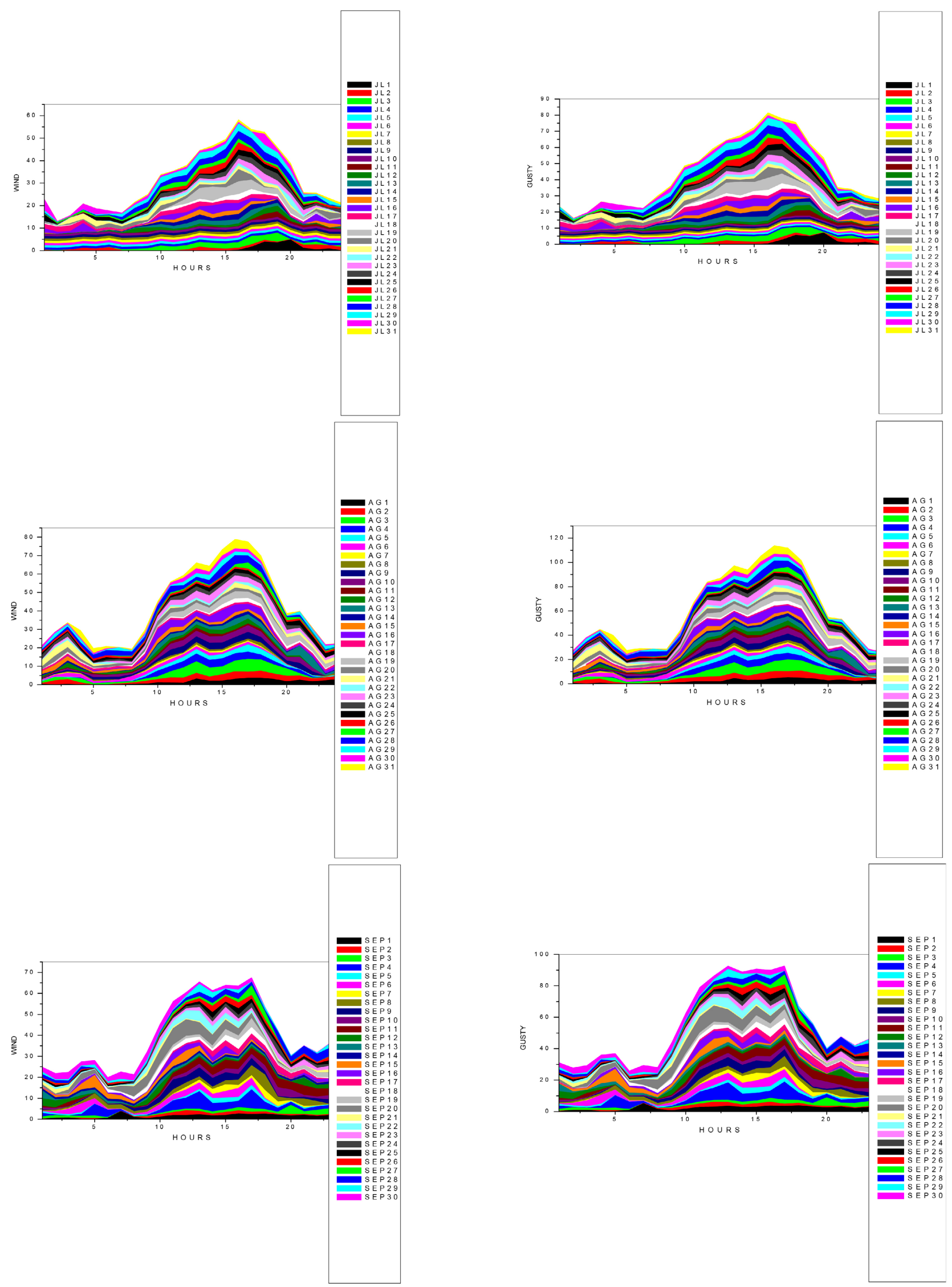

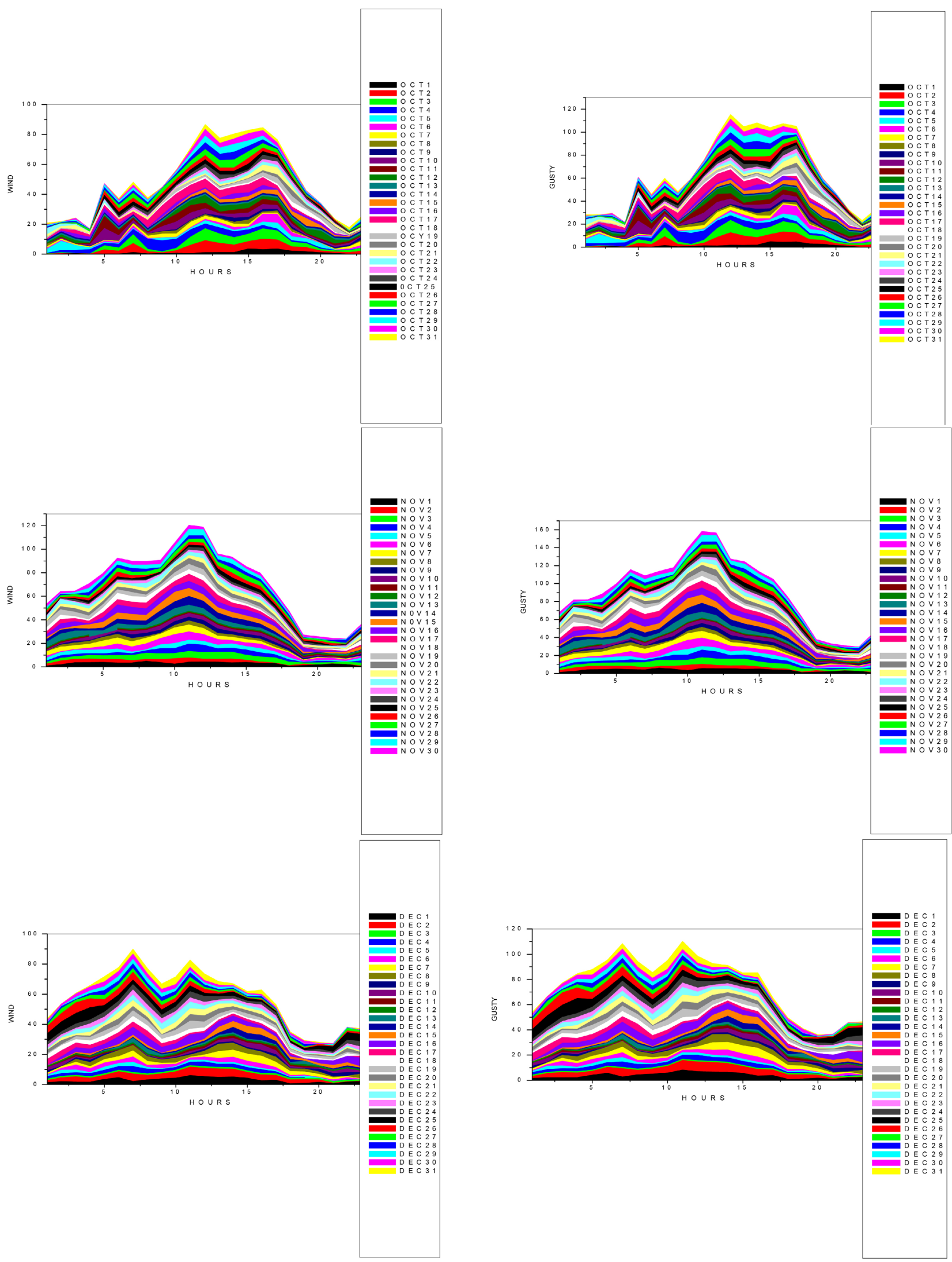

Figure 4. Diurnal variations in the wind speeds and the Gust winds for each month of the year 2020. 
dry season is prevalent under the influence of the north-east winds). The month of March had a holistic change in the shape of the trend, the time of peak and it now follows the usual diurnal trend (low in the early morning, high in the afternoon and low at night). The change in both parameters was very drastic, and what caused it must definitely be a "major" thing. I strongly believe, it is as a result of the movement of the Sun. The Sun crosses the Equator and moves northward in March, thus leading to high temperature around March-April in the region [4]. The effect of the crossing is experienced in both months (temperature and winds). No wonder, the graphs of the two months (both in wind speeds and gust winds) reflect a chaotic pattern throughout the whole month. This pattern only occurred in the two months (March and April) out of the whole year. Even though March, April, May, June, August, October, November and December had their early morning values stronger the nightime values. The month of November and December had stronger early morning values than other months as seen from the graph. This could be as a result of the presence of the Northeast winds (early stages of the dry season at the location). Figures 5 shows that, there are more stronger wind speeds and gust winds in the months of the dry season (October till March) than in the months of the rainy season (April till September). This is in agreement with [4] [17] [27].

Figure 5 shows the gust factor of the measured wind speeds and gust winds. The month of January had the highest values, with April being the next, then February. After that May, then March. Meanwhile, June, July, October, November and December showed particularly very low values when compared with others. The month of January and April had highly very strong values during the daytime than the early morning or nighttime. The month of February had roughly strong values across the three stages. March had stronger values at the early morning. May had almost uniform values across the three stages. June had stronger values at the early morning. July had almost uniformly values across the three stages. August had stronger values at early morning up to 12:00 hrs and then at night time. September had stronger values at the early morning up to 09:00 hrs then latter in the night time. October had more stronger values at the early morning up to roughly 12:00hrs. However, November and December showed similar scenario as both had stronger values at the night-times. The higher the Gust factor, the lower the wind speed and vice versa. The gust factor is said to be a crude representation of the dynamic properties of the wind. Its forecasting is considered very vital in different areas highlighted earlier in the paper. [26] revealed that knowing the time of high or low speeds is very important for load estimation on large structures in exposed locations. The Peak factor of the whole months in the year 2020 as seen in Figure 6 clearly showed that January and April stood out from the rest. In terms of being the months with the highest positive values and highest number of negative values (April first then January). April had its stronger values almost 3 times that of January. The next month after January was March (but no negative value at all), then May (only 

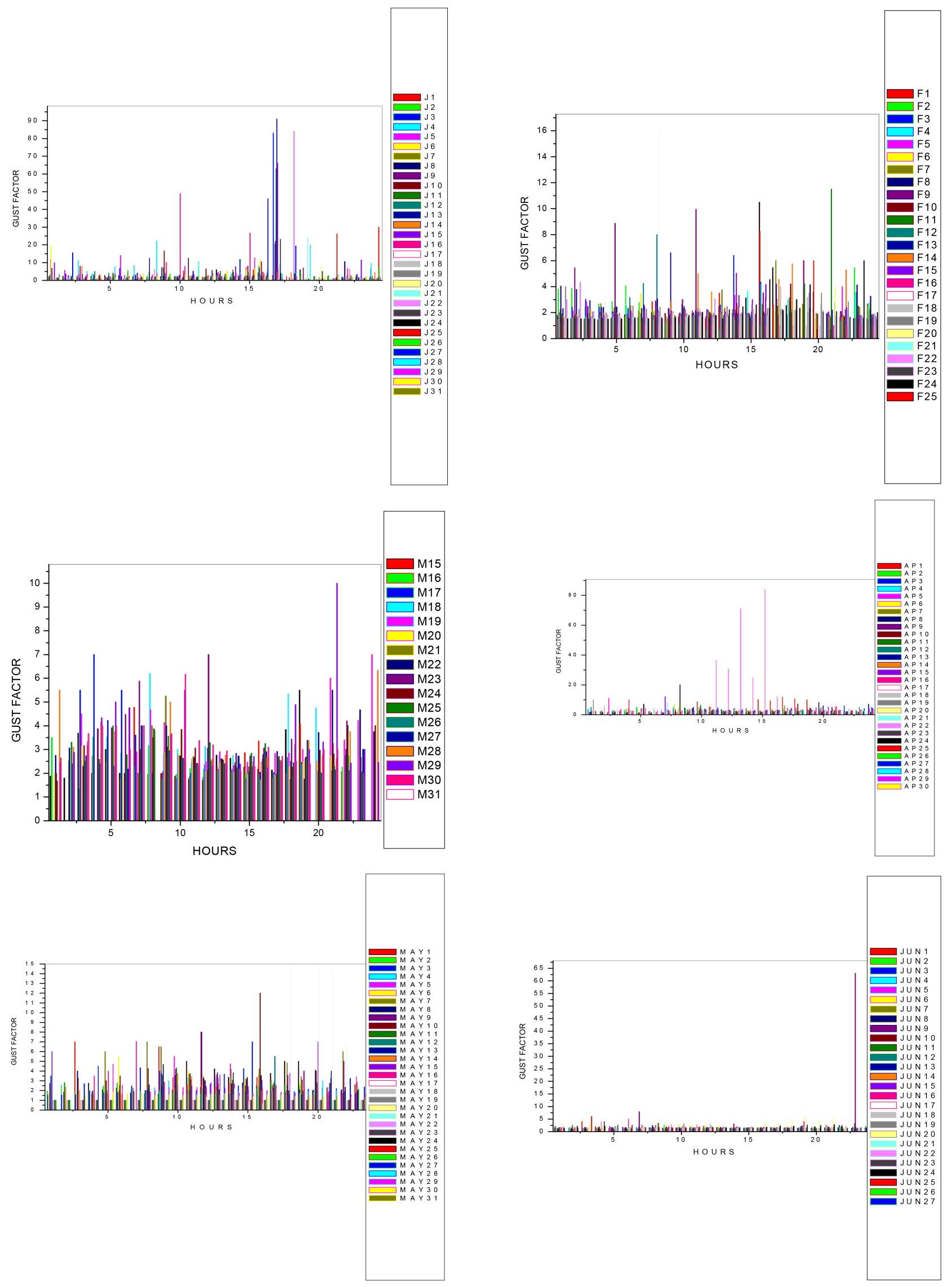

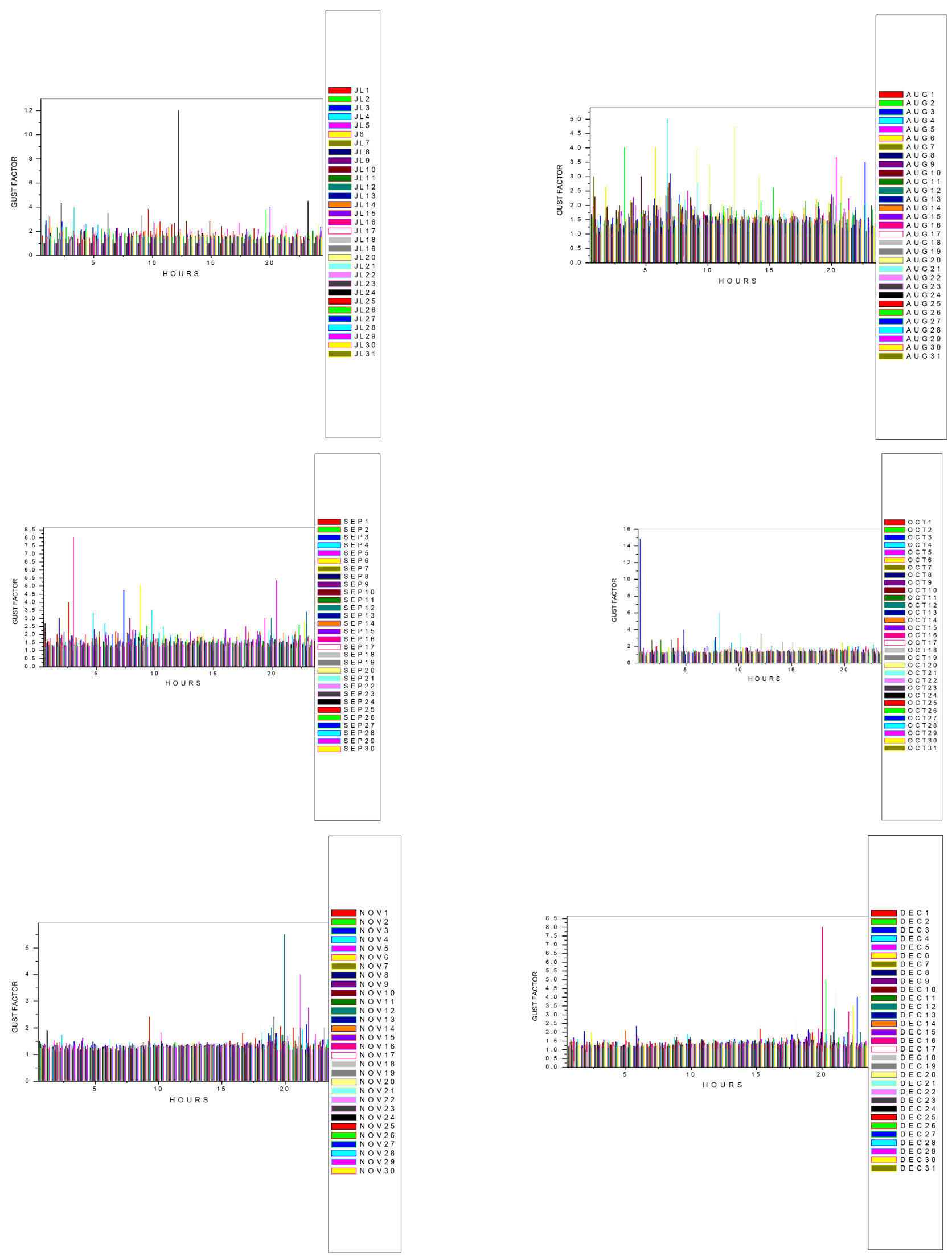

Figure 5. Gust Factor for each of the hour for the whole months of the year 2020. 

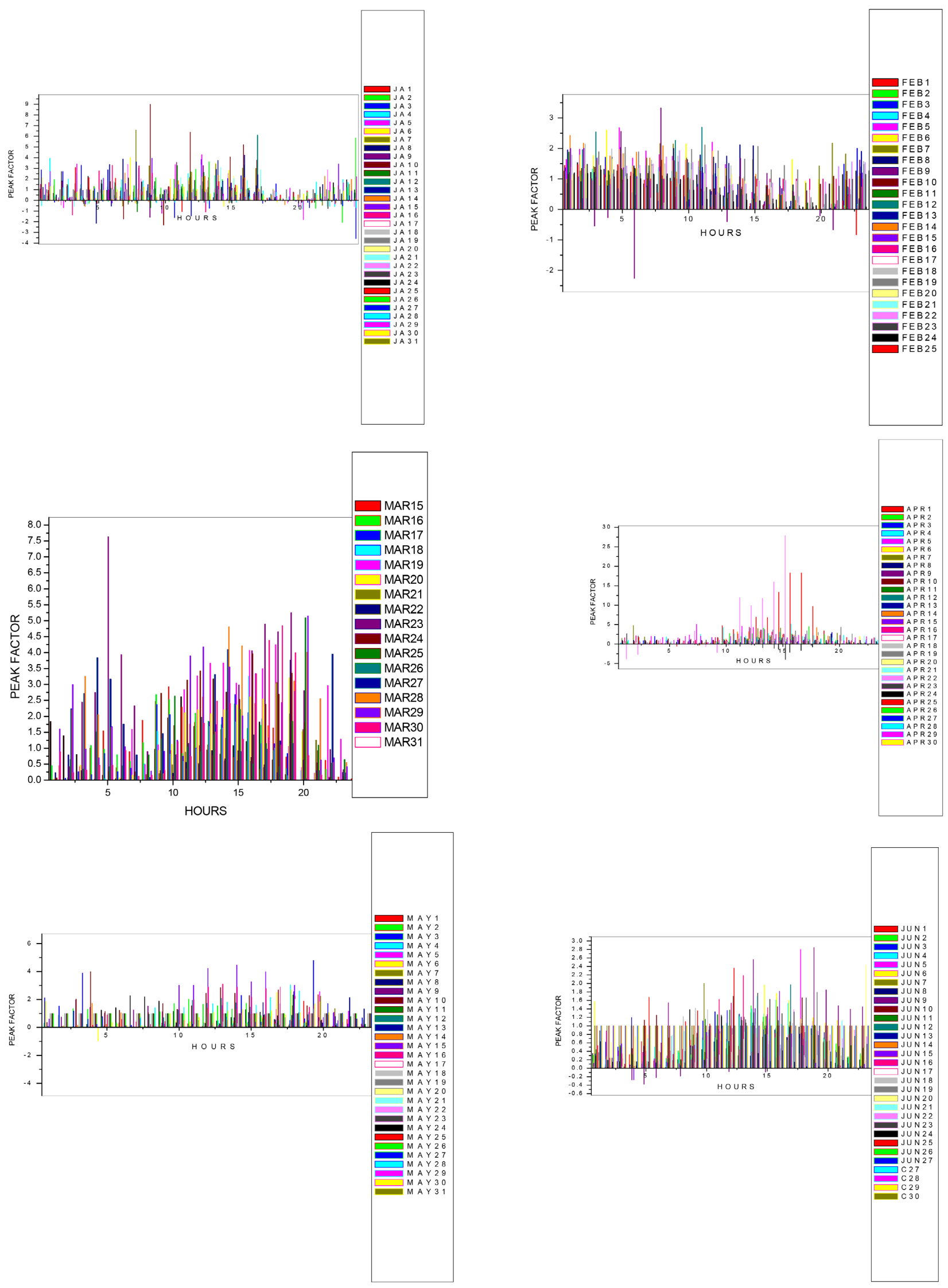

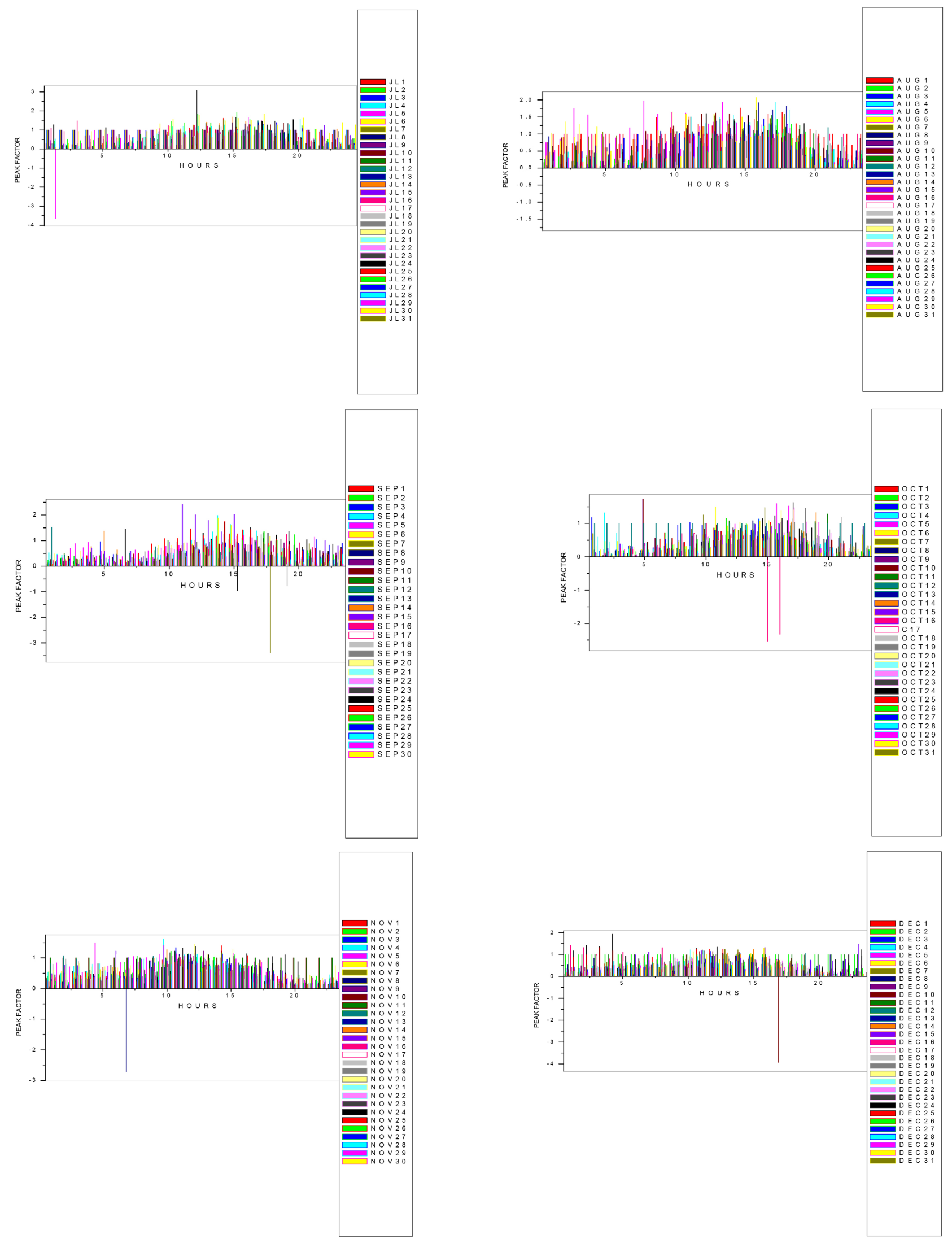

Figure 6. Peak factor for each of the hour for the whole months of the year 2020. 
one negative value). The month of December was the least. This leads to the month of December having the strongest wind speeds in the year. [27] showed that atmospheric stability relates squarely to both intensity and length scale of turbulence. This makes gust factor to be lower for stable conditions. However, [26] showed that the peak factor is less sensitive to stability, but shows a slightly deceasing trend with increased stability. While Gust factor showed January, April, February and May in that order. Peak factor showed April, January, March and May in that order. It was clear from the earlier results that March and April as shown in Figure 5 due to the movement of the Sun at that time (Considering the location of the station too) had a strong impact on the measured wind speeds and gust winds as showed by their graphs. [26] states that by using the peak factor (which includes the turbulence intensity), the dependence on turbulence and atmospheric stability is reduced, but still present. The results showed by the Peak factor $\left(K_{P T_{r}}\right)$ is clearly a better measure for gustiness than Gust factor.

Figure 7 shows stronger values in both parameters in the months in the dry season (January, February, November and December). The figure also shows a rough increasement in the values of the mean of both parameters as the month moves through the raining season. Both parameters also exhibited very strong depression from February to March (the strongest in the whole data). Figure 8 however, shows similar trend in both parameters with the deepest depression from February to March. Figure 7 and Figure 9 clearly show that the relationship between the Wind speeds and Gust wind speeds were linear with significant coefficient of determination $\left(R^{2}\right)$ of 0.9653 .

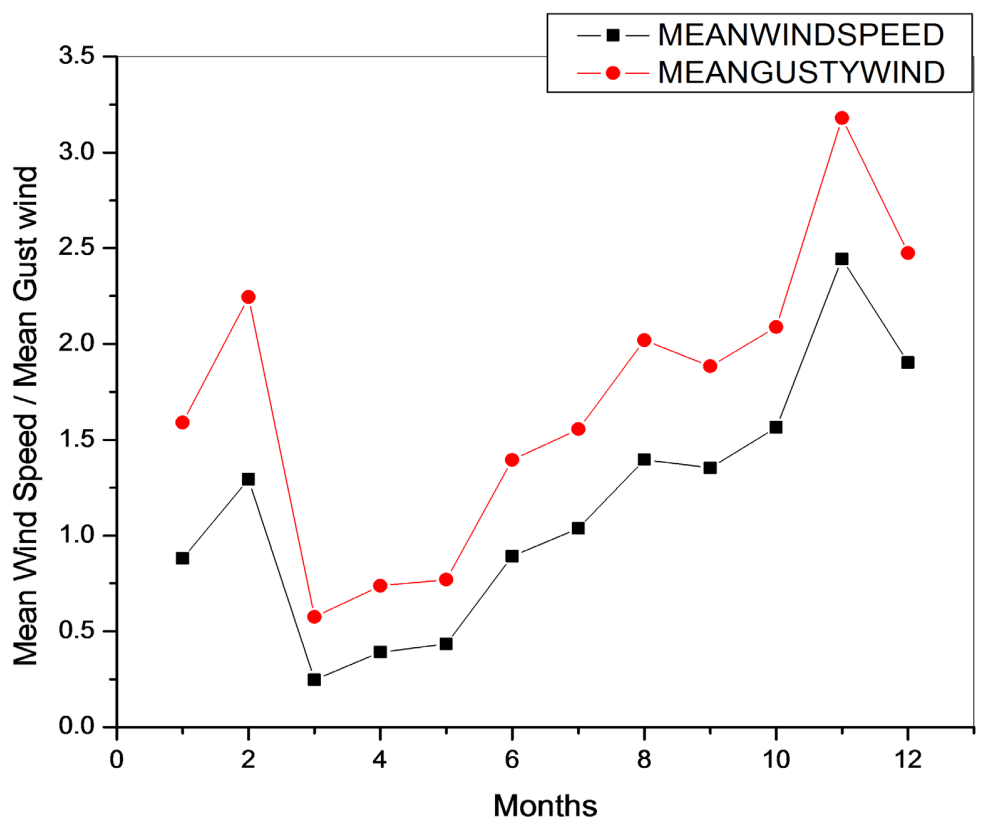

Figure 7. Mean wind speed and mean gust wind speed for each month of the year 2020 . 


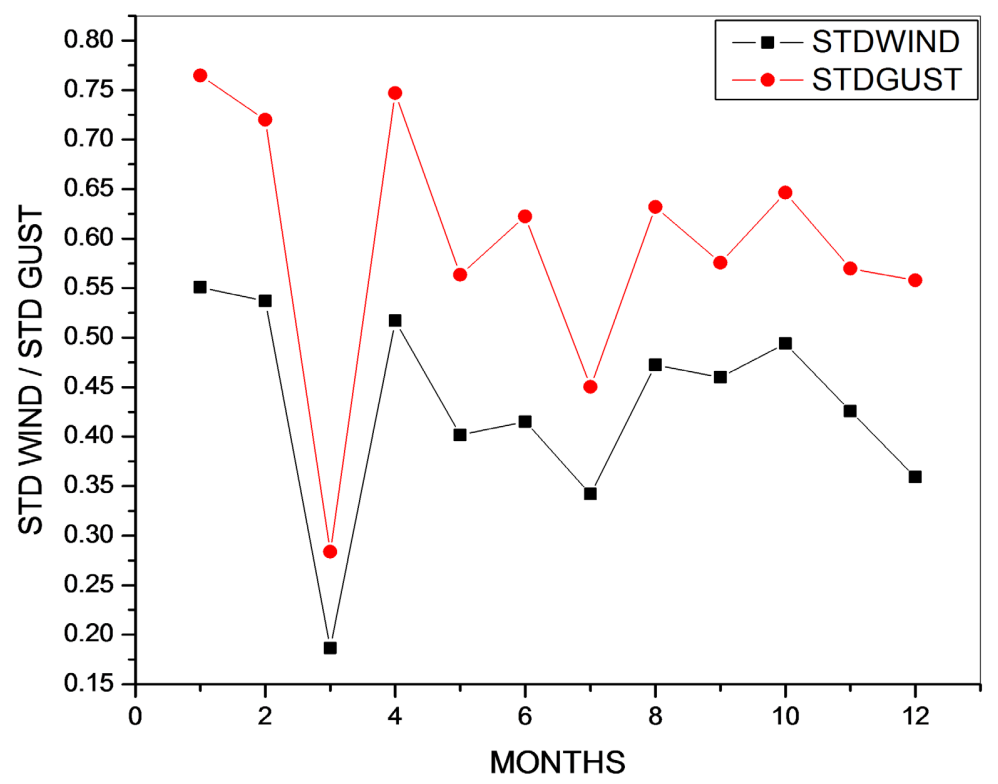

Figure 8. Standard deviation of the wind speed and gust wind speed for each month of the year 2020 .

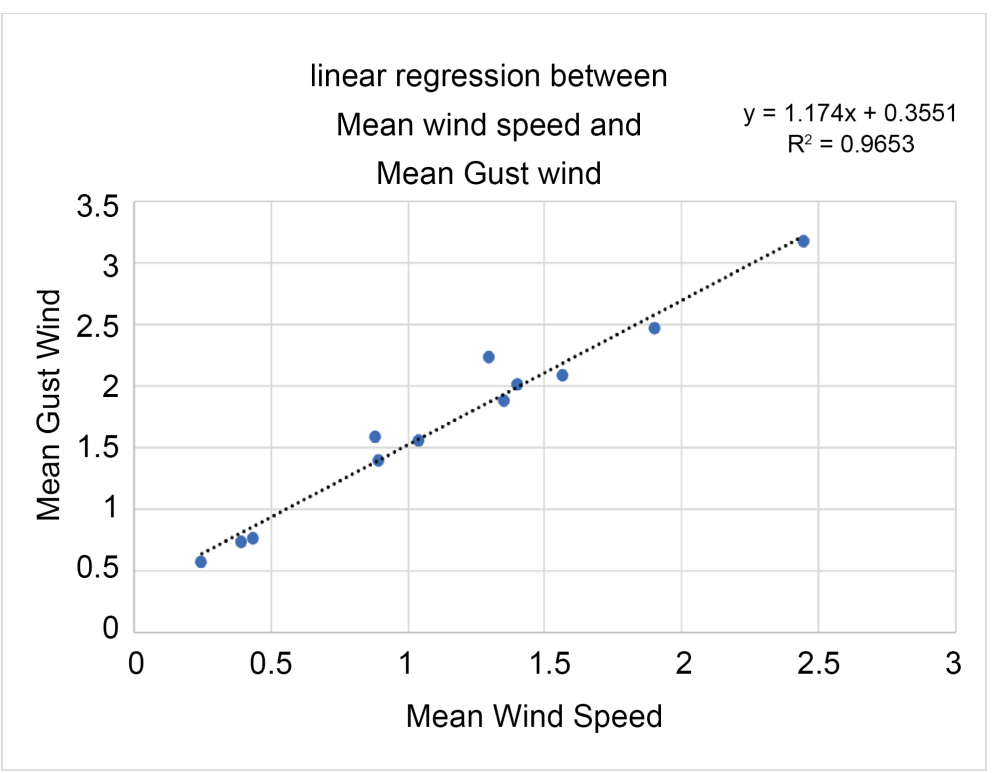

Figure 9. The relationship between mean gust wind and mean wind speed at Abuja, Nigeria for 2020.

\section{Conclusions}

This paper throws up some very interesting detailed information about the inter-relationship between maximum and average wind speeds at this specific location. One of them was, the unique scenario between the wind speed and gust wind speed of January and February, 2020. The strong reversal in the trend of both parameters from March till December was another main point of the paper. The impact of the change in the trade wind (from North east trade wind to southwest trade wind) from February to March and from Southwest trade wind 
to northeast trade wind from September to October was clearly seen in the results.

The use of the gust factor also revealed that the month of June till December had far stronger wind speeds than January to May. However, the use of Peak Factor which is a far better measure of gustiness according to [26]. [26] showed that the peak factor is less sensitive to stability, but also shows a slightly decreasing trend with increased stability.

This invariably means that the Peak factor showed increasing trend with decreasing stability. Nigeria being located in the tropical region where the atmosphere is warm throughout the year automatically makes Peak factor a better option.

\section{Acknowledgement}

Special appreciation goes to Mr Ghatikar

(https://www.wunderground.com/dashboard/pws/IABUJA3) for making the station available for us to use the data.

\section{Conflicts of Interest}

The authors declare no conflicts of interest.

\section{References}

[1] Schwanghart, W. and Schutt, B. (2007) Meteorological Causes of Harmattan Dust in West Africa. Geomorphology, 95, 412-428. https://doi.org/10.1016/j.geomorph.2007.07.002

[2] Getis, A., Getis, J., Bjelland, M. and Fellmann, J.D. (2011) Introduction to Geography. 13th Edition, The McGraw-Hill Companies, Inc., New York.

[3] Udo, I.A. and Okujagu, C.U. (2014) Assessment of Inter-Tropical Convergence Zone (ITCZ) Impact on Precipitation in Six Locations in Nigeria. International Journal of Science and Research (IJSR), 3, 2736-2739.

[4] Salau, O.R. (2017) The Links between Variations in Climate Patterns and ITCZ Position over Nigeria. World Scientific News, 87, 191-204.

https://doi.org/10.1175/1520-0442(1996)009\%3C2958:WTIIMN\%3E2.0.CO;2

[5] Philander, S.G.H., Halpern, D., Gu, D.G., Lambert, N.-C., Lau, T.L. and Pacanowski, R.C. (1996) The Role of Low-Level Stratus Clouds in Keeping the ITCZ Mostly North of the Equator. Journal of Climate, 9, 2958-2972.

[6] Oyewole, J.A. and Aro, T.O. (2018) Wind Speed Pattern in Nigeria (A Case Study of Some Coastal and Inland Areas). Journal of Applied Sciences and Environmental Management, 22, 119-123. https://doi.org/10.4314/jasem.v22i1.22

[7] Ododo, J.C. (1994) New Models for the Prediction of Solar Radiation in Nigeria. Proceedings of the 2nd OAUISTRC Conference on New, Renewable and Solar Energies, Bamako, 16-20 May 1994, 16-20.

[8] Adler, R.F., Huffman, G.J., Chang, A., Ferraro, R., Xie, P., Janowiak, J., Rudolf, B., Schneider, U., Curtis, S., Bolvin, D., Gruber, A., Susskind, J. and Arkin, P. (2003) The Version 2 Global Precipitation Climatology Project (GPCP) Monthly Precipitation Analysis (1979-Present). Journal of Hydrometeorology, 4, 1147-1167. https://doi.org/10.1175/1525-7541(2003)004\%3C1147:TVGPCP\%3E2.0.CO;2 
[9] Gipe, P. (1998) Overview of Worldwide Wind Generation. Renewable Energy, 15, 78-82.

[10] Zhang, Z., Wang, K., Chen, D. and Li, J. (2019) Increase in Surface Friction Dominates the Observed Surface Wind Speed Decline during 1973-2014 in the Northern Hemisphere Lands. Journal of Climate, 32, 7421-7435.

https://doi.org/10.1175/JCLI-D-18-0691.1

[11] Suomi, I. and Vihma T. (2018) Wind Gust Measurement Techniques-From Traditional Anemometry to New Possibilities. Sensors, 18, Article No. 1300. https://doi.org/10.3390/s18041300

[12] Sheridan, P. (2011) Review of Techniques and Research for Gust Forecasting and Parameterization. Forecasting Report Technical Report No. 570. Met Office, Devon.

[13] Danlami, D. (2017) Spatio-Temporal Variations of Harmattan Season in Northeastern Nigeria. M.Sc. Dissertation, Submitted to the Department of Geography, Bayero University, Kano. (Not Published)

[14] Karabulut, M., Demirci, A. and Kora, F. (2012) Analysis of Spatially Distributed Annual, Seasonal and monthly temperatures in Istanbul from 1975 to 2006 . World Applied Sciences Journal, 12, 1662-1675.

[15] Amadi, S.O., Udo, S.O. and Ewona, I.O. (2014) Trends in Monthly Mean Minimum and Maximum Temperature Data over Nigeria for the Period 1950-2012. International Research Journal of Pure and Applied Physics, 2, 1-27.

[16] Danlami, D., Idris, S., Thlakma, R.S. and Gwandum, G.S., (2019) The Spatio-Temporal Variations of Wind Speed during Harmattan Season in Northeastern Nigeria. Geosfera Indonesia, 4, 105-123. https://doi.org/10.19184/geosi.v4i2.11474

[17] Sasaki, R., Akahoshi, A. and Uematsu, Y. (2015) Relationship between Surface Roughness and Turbulence of Natural Winds near the Ground Surface. Technical Transactions Civil Engineering Budownictwo Zeszyt, 2-B, 317-330.

[18] Prahl, B., Rybski, D., Burghoff, O. and Kropp, J. (2015) Comparison of Storm Damage Functions and Their Performance. Natural Hazards and Earth System Sciences, 15, 769-788. https://doi.org/10.5194/nhess-15-769-2015

[19] Solari, G., Repetto, M.P., Burlando, M., De Gaetano, P., Pizzo, M., Tizzi, M. and Parodi, M. (2012) The Wind Forecast for Safety Management of Port Areas. Journal of Wind Engineering and Industrial Aerodynamics, 104-106, 266-277. https://doi.org/10.1016/j.jweia.2012.03.029

[20] Chan, P. (2012) An Event of Tail Strike of an Aircraft Due to Terrain-Induced Wind Shear at the Hong Kong International Airport. Meteorological Applications, 19, 325333. https://doi.org/10.1002/met.264

[21] Shi, X.K., Liu, J.W., Li, Y.D., Huang, B. and Tan, Y.Q. (2015) A Diagnostic Method for Aircraft Turbulence Based on High-Resolution Numerical Weather Prediction Products. Natural Hazards, 77, 867-881. https://doi.org/10.1007/s11069-015-1630-0

[22] Burton, T., Sharpe, D., Jenkins, N. and Bossanyi, E. (2011) Wind Energy Handbook. 2nd Edition, John Wiley \& Sons, Chichester, 742.

https://doi.org/10.1002/9781119992714

[23] Wang, X., Guo, P. and Huang, X. (2011) A Review of Wind Power Forecasting Models. Energy Procedia, 12, 770-778. https://doi.org/10.1016/j.egypro.2011.10.103

[24] Vajda, A., Tuomenvirta, H., Juga, I., Nurmi, P., Jokinen, P. and Rauhala, J. (2014) Severe Weather Affecting European Transport Systems: The Identification, Classification and Frequencies of Events. Natural Hazards, 72, 169-188.

https://doi.org/10.1007/s11069-013-0895-4 
[25] Bardal, L.M. and Sætran, L.R. (2016) Wind Gust Factors in a Coastal Wind Climate. Energy Procedia, 94, 417-424. https://doi.org/10.1016/j.egypro.2016.09.207

[26] Waewsak, J., Chancham, C., Landry, M. and Gagnon, Y. (2011) An Analysis of Wind Speed Distribution at Thasala, Nakhon Si Thammarat, Thailand. Journal of Sustainable Energy \& Environment, 2, 51-55.

[27] Monahan, H.H. and Armendariz, M. (1971) Gust Factor Variations with Height and Atmospheric Stability. Journal of Geophysical Research, 76, 5807-5818.

https://doi.org/10.1029/JC076i024p05807 